\title{
Review of smoking cessation treatments for people with mental illness ${ }^{\dagger}$
}

\author{
Jonathan Campion, Ken Checinski \& Jo Nurse
}

\begin{abstract}
This article reviews the current literature regarding treatments for smoking cessation in both the general population and in those with mental health problems. The gold-standard treatment for the general population is pharmacotherapy (nicotine replacement therapy, bupropion or varenicline) coupled with individual or group psychological support. This is also effective in helping people with mental illness to reduce or quit smoking, but care must be taken to avoid adverse medication interactions and to monitor antipsychotic medication in particular as cigarette consumption reduces.
\end{abstract}

This is the first of two articles in this issue by Campion et al. The second (pp. 217-228) considers the epidemiology and physiology of smoking by people with mental illnesses, and the benefits of quitting. For a discussion of implementation of smoking bans in mental health services with particular reference to UK legislation see pp. 198-207.

For people with mental illness, high rates of smoking result in significantly increased risk of many smoking-related diseases, and it is likely that this is responsible for most of the excess natural mortality of this group (Brown et al, 2000). However, although they are about twice as likely to smoke, people with mental illness are also able to quit (Lasser et al, 2000). Around half of smokers with mental health problems in the UK have expressed a desire to stop smoking (Jochelson \& Majrowski, 2006). Those whose mental illness has remitted are at no greater risk for subsequent smoking than those with active disorders (Breslau et al, 2004). In the general population, smoking increases the risk of developing a mental illness even after correcting for major risk indicators of mental disorder (Cuijpers et al, 2007) and therefore smoking cessation may prevent mental as well as physical illness.

Although there has been less research specifically focusing on smokers with mental health problems, treatments are known to be effective in helping them to stop (McNeill, 2004). However, such treatments

${ }^{+}$See pp. $198-207$ and $217-228$, this issue. are not being offered routinely. In this article we summarise our findings on smoking cessation treatments in general, and then comment more specifically on particular mental health problems.

To review the literature on smoking cessation in people with mental health problems, Medline and the Cochrane reviews were searched using the keywords smoking, schizophrenia, depression and cessation. The findings are divided into those relevant to the general population and those for populations with mental health problems.

\section{Smoking cessation interventions for the general population}

The gold standard for help with smoking cessation (Box 1) is pharmacotherapy plus individual or group specialist behavioural support (West et al, 2004), which approximately quadruples the chance of successfully stopping. Nicotine replacement therapy (NRT), bupropion and varenicline are proven costeffective treatments, although the majority of smokers relapse after treatment (Cahill et al, 2007; Hughes et al, 2007; Stead et al, 2008).

\section{Nicotine replacement therapy}

Six forms of NRT are currently available in the UK: gum, patch, inhalator, nasal spray, tablet and lozenge. These products come in a variety of doses

\footnotetext{
Jonathan Campion is a specialist psychiatry registrar on the St George's Psychiatry Training Scheme in London (Springfield Hospital, 61 Glenburnie Road, London SW17 7DJ, UK. Email: jonathan_campion@yahoo.co.uk). Areas of interest and research include public mental health, addiction, transcultural psychiatry and mental health service provision in low income countries. Ken Checinski is a senior lecturer in addictive behaviour at St George's, University of London, and consultant psychiatrist with the Respond NHS substance misuse service in Surrey. Research and clinical interests include smoking and mental health, dual diagnosis, post-traumatic stress and public health education. Jo Nurse is national lead for public mental health and well-being at the Department of Health, England. She works as a consultant in public health in a regional public health group. Areas of interest and experience include health promotion, sexual health, healthy prison settings, mental well-being, substance misuse, violence and abuse.
} 
Box 1 Summary of effective smoking cessation medication

- NRT is effective for smoking cessation

- Combining different forms of NRT enhances cessation rates

- Pre-loading with NRT may increase cessation rates

- Use of NRT alongside a reduction in cigarette consumption may also be useful as a first step towards cessation for heavier dependent smokers

- Bupropion and nortriptyline are effective but SSRIs and anxiolytics do not improve cessation rates

- Bupropion reduces withdrawal symptoms as well as weight gain

- Varenicline is also effective and may be more effective than bupropion

and flavours. The products also vary in their speed of nicotine delivery. A recent review found that the risk ratio of abstinence for any form of NRT relative to control was 1.58 (Stead et al, 2008). Although risk ratios of abstinence varied depending on the type of NRT, there was overlap of confidence intervals (Table 1). However, further analyses found that risk ratios of abstinence were significantly higher for tablets/lozenges than for gum $(P=0.014)$ and that nasal spray was marginally significant over gum $(P=0.055)$ (Stead et al, 2008).

\section{Combined forms of NRT}

Combining a nicotine patch with a rapid-delivery form of NRT is more effective than a single type of nicotine replacement (Stead et al, 2008). Therefore, it would seem that rapid-delivery NRT such as nasal sprays deal with breakthrough urges, whereas nicotine patches provide background nicotine replacement. The effectiveness of NRT appears to be largely

\begin{tabular}{|c|c|c|c|}
\hline Form of replacement & $R R$ & $95 \% C I$ & Trials, $n$ \\
\hline Any form & 1.58 & $1.50-1.66$ & \\
\hline Nasal spray & 2.02 & $1.49-3.73$ & 4 \\
\hline Tablets/lozenges & 2.00 & $1.63-2.45$ & 6 \\
\hline Inhalers & 1.90 & $1.36-2.67$ & 4 \\
\hline Patches & 1.66 & $1.53-1.81$ & 41 \\
\hline Gum & 1.43 & $1.33-1.53$ & 53 \\
\hline
\end{tabular}

independent of the intensity of additional support provided to the individual (Stead et al, 2008).

NRT while smoking

There is some evidence that using the nicotine patch for a short period before the quit attempt results in higher cessation rates (Stead et al, 2008). Using NRT alongside a reduction in cigarettes is sometimes helpful for heavy smokers who find cessation in one step too difficult. Systematic reviews found that NRT while smoking significantly increases the likelihood of long-term abstinence (increase in risk ratio $\mathrm{RR}=2.06,95 \%$ CI 1.34-3.15; Wang et al, 2008) and the odds of cessation (increase in $R R=1.90,95 \%$ CI 1.46-2.47; Stead \& Lancaster, 2007). However, insufficient evidence exists about long-term benefits of interventions intended to help smokers reduce but not stop smoking.

The Medicines and Healthcare products Regulatory Agency \& Committee on Safety of Medicines (2005) have enabled some NRT products (some forms of gum and inhalators) to be used for smoking reduction as a first step towards cessation and, more recently, some forms of gum and lozenge have been given indications for use during periods of temporary abstinence from smoking.

\section{Bupropion and nortriptyline}

A systematic review (Hughes et al, 2007) showed that the antidepressant bupropion doubles smoking cessation rates (odds ratio $\mathrm{OR}=1.94,95 \% \mathrm{CI}$ $1.72-2.19)$ as does nortriptyline $(\mathrm{OR}=2.34,95 \% \mathrm{CI}$ 1.61-3.41). However, selective serotonin reuptake inhibitors (SSRIs) and anxiolytics do not improve cessation rates (Hughes et al, 2007), suggesting that the mode of action of bupropion and nortriptyline is independent of their antidepressant effect. There is insufficient evidence on whether the combination of NRT with bupropion or nortriptyline increases cessation rates (Hughes et al, 2007). Bupropion reduces withdrawal symptoms as well as weight gain (Richmond \& Zwar, 2003).

\section{Varenicline}

Varenicline is a nicotine receptor partial agonist and is thought to act both as an agonist maintaining moderate levels of dopamine to counteract withdrawal symptoms and as an antagonist by reducing smoking satisfaction. It became available in the UK in December 2006. A systematic review (Cahill et al, 2007) reported that varenicline increases the odds of cessation by 3.22 (95\% CI 2.43-4.27) compared with placebo and by 1.66 (95\% CI 1.28-2.16) compared with bupropion. Varenicline 
had fewer serious side-effects than bupropion and showed high patient satisfaction.

\section{Rimonabant}

Rimonabant is a selective type 1 cannabinoid receptor antagonist. A review concluded that rimonabant at $20 \mathrm{mg}$ daily increased the odds of smoking cessation by 1.61 (95\% CI 1.12-2.30), although at $5 \mathrm{mg}$ it had no effect (Cahill \& Ussher, 2007). It has potential to protect those who successfully stop from gaining weight, although the evidence for maintaining abstinence is inconclusive. However, concern has been raised over increased rates of depression and suicidal thoughts in those taking rimonabant.

\section{Naltrexone}

There are insufficient data regarding whether naltrexone is helpful for smoking cessation (David et al, 2006).

\section{Adverse effects of pharmaceutical interventions}

\section{Nicotine replacement therapy}

The effects of nicotine acquired through NRT are thought to be no different from those of smokingderived nicotine. Nicotine replacement products can cause gastrointestinal disturbance, headache, dizziness, influenza-like symptoms, dry mouth, rash and palpitations. In addition, nasal spray can cause irritation of nasal mucosa, sneezing, epistaxis and watering eyes; patches can cause sleep disturbance, nightmares and local skin irritation, and their use is cautioned for people with widespread skin disorders such as psoriasis or dermatitis; nicotine gum can cause stomach irritation; inhalators can cause coughing; lozenges can cause stomach irritation, thirst, sleep disturbance and nightmares; gum, lozenges, sublingual tablets and inhalators can produce hiccups or throat irritation (British Medical Association \& Royal Pharmaceutical Society of Great Britain, 2008).

\section{Bupropion}

The most common side-effect of bupropion is insomnia (30-40\% of individuals), dry mouth (10\%) and nausea. Other documented side-effects include pruritis, irritability, tremor, impaired concentration, headache, dizziness, depression, agitation, anxiety, and less commonly, confusion and visual disturbances (British Medical Association \& Royal Pharmaceutical Society of Great Britain, 2008). Rarely, hallucinations, depersonalisation, dystonia, ataxia, abnormal dreams, memory impairment, and very rarely Stevens-Johnson syndrome, delusions, and aggression have been reported. Seizure is the most significant and important potential side-effect and it occurs at a rate of 1 in 1000, although no randomised controlled trial of bupropion has reported seizures (Hughes et al, 2007). Adverse effects of withdrawal from bupropion include rash, insomnia, tremor, headache, dry mouth, anxiety, psychological problems, drowsiness, weight loss, thinking difficulties, dizziness and palpitations (Woolacott et al, 2002). Bupropion is contraindicated in people with epilepsy (Richmond \& Zwar, 2003) and a history of bipolar disorder (British Medical Association \& Royal Pharmaceutical Society of Great Britain, 2008).

\section{Varenicline}

Side-effects of varenicline include gastrointestinal disturbance such as nausea, dry mouth, taste disturbance, headache, drowsiness, dizziness, sleep disorders and abnormal dreams (British Medical Association \& Royal Pharmaceutical Society of Great Britain, 2008). Less commonly documented side-effects include weight gain, panic attack, abnormal thinking, mood swings, dysarthria, tremor, incoordination, hypertonia and restlessness. It is recommended that abrupt withdrawal of varenicline be avoided because of risk of relapse, irritability, depression and insomnia, and exacerbation of underlying mental illness, including depression.

Case reports describe varenicline's induction of a manic episode in a patient with bipolar affective disorder (Kohen \& Kremen, 2007) and its exacerbation of the symptoms of schizophrenia (Freedman, 2007). Depression and suicidal ideation have been reported (British Medical Association \& Royal Pharmaceutical Society of Great Britain, 2008). These are being reviewed by the European Medicines Agency, which has advised that patients should stop varenicline if they develop suicidal ideation and should contact their doctor immediately.

\section{Rimonabant}

Side-effects of rimonabant include nausea and upper respiratory tract infections (Cahill \& Ussher, 2007).

\section{Potential interactions with other medication}

The Drugs and Therapeutics Bulletin (Anonymous, 2000) advises 'extreme caution' when considering prescribing bupropion to people taking epileptogenic drugs such as tricyclic antidepressants and typical antipsychotics other than butyrophenones. It also 
advises avoidanceinalcohol misuseand amphetamine use because of seizure risk. Carbamazepine reduces levels of bupropion and increases levels of its main metabolite hydroxybupropion (Martinez-Raga et al, 2003); bupropion can also affect blood plasma levels of medications, including some antipsychotics (e.g. risperidone, haloperidol, phenthiazines) and antidepressants (e.g. tricyclic antidepressants, trazodone and SSRIs) (see 'Effects of smoking on psychiatric medication' below).

\section{Non-pharmacological interventions for the general population}

\section{Counselling}

Meta-analyses show that simple advice from a physician has a small but significant effect on smoking cessation $(\mathrm{OR}=1.74,95 \%$ CI 1.48-2.05) (Lancaster \& Stead, 2004). Smoking cessation advice and/or counselling given by nurses significantly increase the likelihood of quitting ( $R R=1.28,95 \%$ CI 1.18-1.38) (Rice \& Stead, 2008), although the evidence is weaker with brief interventions provided by nurses and when counselling is provided by nurses whose main role is not health promotion or smoking cessation. Smoking cessation counselling given face to face by a counsellor trained in smoking cessation is effective, although the evidence is insufficient to demonstrate that intensive counselling is more effective than brief counselling (Lancaster \& Stead, 2005a). Further meta-analysis found that group therapy was more effective than self-help and other less intensive interventions (Stead \& Lancaster, 2005). However, there was not enough evidence to evaluate whether groups are more effective than individual counselling. Meta-analysis shows that telephone support to assist cessation is also effective (Stead et al, 2006) and multiple call-back counselling improves long-term cessation for smokers who contact cessation services (Stead et al, 2007).

\section{Other interventions}

Standard self-help materials are likely to have only a small effect in the general population (Lancaster \& Stead, 2005b). They have no additional benefit when used alongside other interventions such as NRT or advice from a healthcare professional. Incentives and competitions do not improve long-term cessation rates (Hey \& Perera, 2005). Meta-analysis of trials also reveals no benefit for acupuncture (White $e t$ $a l, 2006)$ and hypnotherapy (Abbot et al, 1998). However, there is some evidence for the effectiveness of internet support to aid cessation in those already using NRT (Zwartz et al, 2006).

\section{Relapse prevention}

Smoking cessation has high relapse rates: many people in the general population return to smoking within a year of giving up (Lancaster et al, 2006). Evidence does not yet support the adoption of skills training or other specific interventions to help those who have given up smoking to avoid relapse.

\section{Exercise}

Asystematic review of 12 studies that compared exercise with a passive condition found positive effects on cigarette cravings, withdrawal symptoms and smoking behaviour. This suggests that exercise can be a useful aid to managing cigarette cravings and withdrawal symptoms (Taylor, A.H. et al, 2007).

\section{Adolescents and young people}

Most tobacco-control programmes for adolescents are based on prevention of uptake, since those who do not smoke before the age of 20 are significantly less likely to start as adults. Further high-quality trials are needed to identify effective tobacco cessation interventions for young people (Grimshaw \& Stanton, 2006). In the UK, the only smoking-cessation medication licensed for young people is NRT, and then only from 12 years of age.

\section{Smoking cessation for people with mental health problems}

There is less research on smoking cessation in those with mental health problems despite this group's higher rates of smoking. The following section highlights research evidence specifically among people with different mental health problems and it is worth noting that most of the medication trials also included behavioural support.

\section{Depressive disorders}

Anumber of medical and psychological interventions for smoking cessation used in the general population can be implemented in psychiatric settings for those in treatment for depression. These are summarised in Box 2 and discussed in a little more detail below.

There is evidence that a minority of people experience an increase in depressive symptoms after they stop smoking (Hughes, 2007), so smokers with depression would benefit from closer monitoring following smoking cessation. Increases in depressive symptoms during an initial period of abstinence 
Box 2 Summary of medication and psychological treatment for those with depression

- NRT can double cessation rates and lower self-reported depression in depressed smokers

- One study showed that extended use of bupropion for relapse prevention was effective for smokers with and without a history of major depression

- Psychological and lifestyle strategies assisted in mood regulation over and above the standard smoking cessation treatments for smokers with a depression history

- Structured psychological approaches to smoking cessation added to the benefits of antidepressants and NRT particularly for smokers with high nicotine dependence and repeated episodes of major depression

- CBT doubled abstinence rates in a trial of smokers with recurrent depression

- Increased cessation rates for those being treated for depression occurred through addition of counselling and computerised motivational feedback

have been associated with a return to smoking (Hayford et al, 1999). However, meta-analysis shows that a lifetime history of major depression is not an independent risk factor for failure in smoking cessation treatments (Hitsman et al, 2003).

\section{Nicotine replacement therapy}

Nicotine patches were associated with significantly greater positive mood over time compared with nicotine gum in a study of 335 smokers from the general population (Strasser et al, 2005). A systematic review concluded that nicotine gum reduces total withdrawal discomfort, irritability and anxiety, with some evidence for a positive effect on depressed mood and craving (West \& Shiffman, 2001).

Nicotine replacement doubled cessation rates and significantly lowered self-reported depression in 269 smokers with current depression (Kinnunen et al, 1996). Negative mood peaked in the week following cessation and was linked to higher relapse rates, which highlighted the importance of NRT in those with depression.

Bupropion is effective for smoking cessation for people with and without a history of depression or alcoholism (Richmond \& Zwar, 2003). One study has shown that extended use of bupropion for relapse prevention was effective for smokers with and without a history of major depression (Cox et $a l, 2004)$. Varenicline has not been assessed in trials specifically for smokers with depression. A recent case report advises that varenicline induced a manic episode in a patient with bipolar affective disorder (Kohen \& Kremen, 2007).

For smokers with a history of depression, psychological and lifestyle strategies such as motivational interviewing, relaxation exercises and mood charts can help to regulate mood over and above the standard smoking cessation treatments (Wilhelm et al, 2004). This group requires more attention to relapse of both depression and smoking after cessation.

Structured psychological approaches to smoking cessation add to the benefits of effective smoking cessation pharmacotherapies particularly for smokers with high nicotine dependence and repeated episodes of major depression (Ferguson et al, 2003). In a trial of over 400 smokers with recurrent depression, $35 \%$ of those receiving cognitive-behavioural therapy (CBT) remained abstinent, compared with $18 \%$ receiving health education (Haas et al, 2004).

Staged (stepped) care can also improve cessation rates for people receiving treatment for depression. In one such trial showing positive results, the 322 participants with current depression were offered computerised motivational feedback about their smoking at baseline, 3, 6 and 12 months. They also had provision for 6 sessions of psychological counselling and pharmacotherapy at the appropriate stage of readiness (Hall et al, 2006). Wilhelm et al (2006) had similar success using a series of tiered interventions.

\section{Schizophrenia}

Rates of cessation for smokers with schizophrenia are half those for the general population, partly because of their lower motivation to quit, fewer cessation attempts, increased level of nicotine dependence and reduced access to treatment (Williams \& Foulds, 2007). Neuropsychological deficits in schizophrenia are also implicated (Dolan et al, 2004).

Nevertheless, the literature shows that increased rates of cessation occur with combinations of medication, psychosocial interventions and integration of treatment into overall care plans to reduce the risk of relapse. Box 3 summarises our search findings, which we discuss in a little more detail below.

\section{Pharmacotherapy}

Nicotine replacement is effective for people with schizophrenia, although not as effective as it is for the general population (Williams \& Hughes, 2003). There is some evidence that the rapid nicotine delivery of a nasal spray is most successful (Williams \& Foulds, 


\section{Box 3 Smoking cessation in schizophrenia}

General

- Cessation rates are lower for people with schizophrenia than for the general population

- Specialist cessation services for those with mental illness can achieve higher rates of abstinence

Medication

- Nicotine replacement is effective, although less than in the general population

- Bupropion contributed to reduced smoking and did not worsen clinical symptoms although relapse rate was high after treatment discontinuation

- Combination NRT and bupropion treatment is effective in abstinence and reduction

Combined medication and psychological therapy

- Specialised group therapy plus NRT is effective, and atypical antipsychotics improve abstinence with such treatment

Harm reduction

- Harm reduction approaches include NRT and NRT plus bupropion to reduce the level of smoking, which may improve the chance of future cessation

2007) and cessation rates are likely to be enhanced when it is combined with nicotine patches.

Nicotine replacement therapy may be more successful at improving abstinence in combination with atypical than with typical antipsychotics (George et al, 2000).

\section{Bupropion}

Bupropion can help to reduce smoking in people with schizophrenia (Williams \& Hughes, 2003), and it appears not to exacerbate clinical symptoms of the disorder (Evins et al, 2005). Its modest success in smoking cessation in the latter study, involving 53 individuals, was not maintained after treatment discontinuation, when the relapse rate was high. In a subsequent study (Evins et al, 2007), a combination of NRT and bupropion improved abstinence and reduced cigarette consumption during treatment.

\section{Varenicline}

There are no trials of varenicline for smokers with schizophrenia, but a case report (Freedman, 2007) describes exacerbation of symptoms of the disorder during its use.

\section{Group interventions}

Specialised group therapy programmes and NRT can be effective in smokers with schizophrenia, although less so than in smokers in the general population (Williams \& Hughes, 2003).

\section{Combination interventions}

As previously noted, the majority of trials used a combination of pharmacotherapy and other interventions. A trial of 298 smokers with psychosis found that an eight-session, individually administered smoking cessation intervention using NRT, motivational interviewing and CBT significantly increased the proportion of participants who stopped smoking (Baker et al, 2006).

Specialist services for smokers with schizophrenia and other mental illnesses have used a combination of medication and counselling, and achieved abstinence rates as high as those for people without a history of mental illness (Foulds et al, 2006). These services did not limit the number of contacts, did not require a cessation date and employed an addictions psychiatrist and a mental health social worker who was also a certified tobacco treatment specialist.

\section{Harm reduction approaches}

Nicotine replacement is also used to reduce levels of smoking. A 2-year follow-up study (Evins et al, 2004) showed that people with schizophrenia who reduce the amount they smoke are more likely to quit. As already mentioned, NRT combined with bupropion reduces cigarette consumption (Evins et $a l, 2007)$. Since smokers with schizophrenia spend a considerable amount on tobacco (in the USA, about a third of their monthly income; Steinberg et al, 2004), there are significant financial benefits particularly relevant to the heavier, more dependent smokers found in mental health settings.

\section{Effects of smoking on psychiatric medication}

Smoking affects the metabolism of various psychiatric medications by inducing enzymes in the cytochrome P450 (CYP) system, potentially lowering serum levels of medication by as much as 50\% (Wilhelm et al, 2004). Medication metabolised by CYP1A2 includes diazepam, haloperidol (partial), olanzapine (partial), clozapine, mirtazapine (partial) and tricyclic antidepressants (Bazire, 2003). Liver enzyme induction has also been documented with opiates, 
barbiturates and benzodiazepines (Schall et al, 1996). Smoking can significantly lower serum levels of such medication. Haslemo et al (2006) estimate that a daily consumption of 7-12 cigarettes is probably sufficient for maximum induction of clozapine and olanzapine metabolism, and recommend a 50\% lower starting dose in non-smokers to avoid side-effects.

\section{Effect of smoking cessation on psychiatric medication}

Significantly, if smokers who are stable on a drug metabolised by CYP1A2 enzymes stop smoking, enzyme activity reduces over several days, less medication is metabolised and plasma levels increase. Toxic levels of medication can accumulate in a matter of days. Similarly, plasma levels reduce over days if smoking is resumed.

Clozapine plasma levels have been found to be $40 \%$ lower in smokers than in non-smokers (Seppala et al, 1999). Clozapine toxicity has also been observed during early tobacco abstinence in patients being treated with clozapine (Zullino et $a l, 2002)$. It is therefore recommended that plasma levels are measured before smoking cessation and, for clozapine, olanzapine and fluphenazine, the dose of medication is gradually reduced to $75 \%$ over the subsequent week and a further plasma level is taken 1 week after cessation (Taylor, D. et al, 2007). For benzodiazepines, doses may be reduced by up to $25 \%$ in the first week, and for tricyclic antidepressants dose reductions of $10-25 \%$ over the first week may be required. For all these medications, further dose reductions may be needed.

In summary, in addition to the other health benefits of stopping smoking, lower doses of medication may be required. Attempts to stop smoking should be closely monitored as a clinical issue.

\section{Health economics of smoking cessation}

We could find no published economic evaluations of smoking cessation interventions for people with mental illnesses. However, evaluations for the general population consistently indicate that smoking cessation interventions are relatively costeffective in terms of cost per life-year saved. One UK analysis (Woolacott et al, 2002) estimated that the incremental cost per life-year saved is $£ 1000-2400$ for NRT, $£ 640-1500$ for bupropion and $£ 900-2000$ for NRT plus bupropion. This makes pharmacotherapy for smoking cessation very good value since the average cost per life-year for other interventions is more than $£ 17000$ (Raftery, 2001).

\section{Guidance on smoking cessation in mental illness}

National guidance has been published for health professionals helping people with mental health problems to stop smoking (McNeill, 2004). This stresses the importance of increasing the accessibility of cessation treatments and monitoring attempts to quit, particularly as stopping smoking may affect the metabolism of antipsychotic medication.

Since 2000, a national network of National Health Service (NHS) smoking cessation services has provided support and training to healthcare professionals who interact with smokers in primary and secondary care, as well as offering intensive specialist support for smokers themselves. These services, resources permitting, can provide support and treatment for patients and staff on an ongoing basis, particularly when the NHS's smoke-free policy is being implemented. ${ }^{+}$Health professionals working within mental health settings should receive training on smoking cessation interventions. Although patients can be referred to specialist advisors within the NHS Stop Smoking Services, it would make most sense to integrate and coordinate smoking cessation services within mental health settings where those with more severe mental illness are receiving treatment. This is important since to date, smokefree policies in mental health settings appear to have had little effect on smoking cessation in the longer term, possibly in part because of poor coordination between in-patient, out-patient and smoking cessation services. The Disability Discrimination Act 2005 should assist those with mental health problems to access the same level of smoking cessation service as the general population.

\section{Conclusions}

People with mental health problems tend to smoke more heavily and therefore have higher levels of smoking-related morbidity and mortality. The diagnosis of nicotine dependence and its management with a range of effective treatments will help such individuals to stop smoking. Smoke-free legislation encourages the use of these interventions, which have not been offered routinely to this group. Increased training opportunities for psychiatrists in smoking cessation will assist this process. The result will reduce the negative effects that smoking has on patients' physical and mental health, and will therefore encourage a more health-promoting culture within mental health settings.

${ }^{+}$See pp. 198-207, this issue. 


\section{Acknowledgements}

We are grateful to Professor Ann McNeill (University of Nottingham) for her advice and suggestions.

\section{Declaration of interest}

None.

\section{References}

Abbot, N. C., Stead, L. F., White, A. R., et al (1998) Hypnotherapy for smoking cessation. Cochrane Database of Systematic Reviews, issue 2, CD001008. Update Software.

Anonymous (2000) Bupropion to aid smoking cessation. Drugs and Therapeutics Bulletin, 38, 73-75.

Baker, A., Richmond, R., Haile, M., et al (2006) A randomized controlled trial of a smoking cessation intervention among people with a psychotic disorder. American Journal of Psychiatry, 163, 1934-1942.

Bazire, S. (2003) Psychotropic Drug Directory 2003/2004. Fivepin Publishing.

Breslau, N., Novak, S. P. \& Kessler, R. C. (2004) Psychiatric disorders and stages of smoking. Biological Psychiatry, 55, 69-76.

British Medical Association \& Royal Pharmaceutical Society of Great Britain (2008) British National Formulary. BMJ Books \& Pharmaceutical Press.

Brown, S., Barraclough, B. \& Inskip, H. (2000) Causes of the excess mortality of schizophrenia. British Journal of Psychiatry, 177, 212-217.

Cahill, K. \& Ussher, M. (2007) Cannabinoid type 1 receptor antagonists (rimonabant) for smoking cessation. Cochrane Database of Systematic Reviews, issue 4, CD005353. Wiley InterScience.

Cahill, K., Stead, L. \& Lancaster, T. (2007) Nicotine receptor partial agonists for smoking cessation. Cochrane Database of Systematic Reviews, issue 1, CD006103. Wiley InterScience.

Cox, L. S., Patten, C. A., Niaura, R. S., et al (2004) Efficacy of bupropion for relapse prevention in smokers with and without a past history of major depression. Journal of General Internal Medicine, 19, 828-834.

Cuijpers, P., Smit, F., ten Have, M., et al (2007) Smoking is associated with first-ever incidence of mental disorders: a prospective population-based study. Addiction, 102, 1303-1309.

David, S., Lancaster, T., Stead, L. F., et al (2006) Opioid antagonists for smoking cessation. Cochrane Database of Systematic Reviews, issue 4, CD003086. Wiley InterScience.

Dolan, S. L., Sacco, K. A., Termine, A., et al (2004) Neuropsychological deficits are associated with smoking cessation treatment failure in patients with schizophrenia. Schizophrenia Research, 70, 263-275.

Evins, A. E., Cather, C., Rigotti, N. A., et al (2004) Two-year followup of a smoking cessation trial in patients with schizophrenia: increased rates of smoking cessation and reduction. Journal of Clinical Psychiatry, 65, 307-311.

Evins, A. E., Cather, C., Deckersbach, T., et al (2005) A doubleblind placebo-controlled trial of bupropion sustained-release for smoking cessation in schizophrenia. Journal of Clinical Psychopharmacology, 25, 218-225.

Evins, A. E., Culhane M. A., Birnbaum, A., et al (2007) A 12-week double-blind, placebo-controlled study of bupropion SR added to high-dose dual nicotine replacement therapy for smoking cessation or reduction in schizophrenia. Journal of Clinical Psychopharmacology, 27, 380-386.

Ferguson, D., Goodwin, R. \& Horwood, L. (2003) Major depression and cigarette smoking: results of a 21-year longitudinal study. Psychological Medicine, 33, 1357-1367.

Foulds, J. G. K., Steinberg, M. B., Richardson, D., et al (2006) Factors associated with quitting smoking at a tobacco dependence treatment clinic. American Journal of Health Behaviour, 30, 400-412.

Freedman, R. (2007) Exacerbation of schizophrenia by varenicline. American Journal of Psychiatry, 164, 1269.
George, T. P., Ziedonis, D. M., Feingold, A., et al (2000) Nicotine transdermal patch and atypical antipsychotic medications for smoking cessation in schizophrenia. American Journal of Psychiatry, 157, 1835-1842.

Grimshaw, G. M. \& Stanton, A. (2006) Tobacco cessation interventions for young people. Cochrane Database of Systematic Reviews, issue 4, CD003289. Wiley InterScience.

Haas, A. L., Munoz, R. F., Humfleet, G. L., et al (2004) Influences of mood, depression history, and treatment modality on outcomes in smoking cessation. Journal of Consulting and Clinical Psychology, 72, 563-570.

Hall, S. M., Tsoh, J. Y., Prochaska, J. J., et al (2006) Treatment for cigarette smoking among depressed mental health outpatients: a randomized clinical trial. American Journal of Public Health, 96, 1808-1814.

Haslemo, T., Eikeseth, P. H., Tanum, L., et al (2006) The effect of variable cigarette consumption on the interaction with clozapine and olanzapine. European Journal of Clinical Pharmacology, 62, 1049-1053.

Hayford, K. E., Patten, C. A., Rummans, T. A., et al (1999) Efficacy of bupropion for smoking cessation in smokers with a former history of major depression or alcoholism. British Journal of Psychiatry, 174, 173-178.

Hey, K. \& Perera, R. (2005) Competitions and incentives for smoking cessation. Cochrane Database of Systematic Reviews, issue 2, CD004307. Wiley InterScience.

Hitsman, B., Borrelli, B., McChargue, D. E., et al (2003) History of depression and smoking cessation outcome: a meta-analysis. Journal of Consulting and Clinical Psychology, 71, 657-663.

Hughes, J. R. (2007) Depression during tobacco abstinence. Nicotine and Tobacco Research, 9, 443-446.

Hughes, J., Stead, L. \& Lancaster, T. (2007) Antidepressants for smoking cessation. Cochrane Database of Systematic Reviews, issue 1, CD000031. Wiley InterScience.

Jochelson, J. \& Majrowski, B. (2006) Clearing the Air. Debating Smoke-Free Policies in Psychiatric Units. King's Fund.

Kinnunen, T., Doherty, K., Militello, F. S., et al (1996) Depression and smoking cessation: characteristics of depressed smokers and effects of nicotine replacement. Journal of Consulting and Clinical Psychology, 64, 791-798.

Kohen, I. \& Kremen, N. (2007) Varenicline-induced manic episode in a patient with bipolar disorder. American Journal of Psychiatry, 164, 1269-1270.

Lancaster, T. \& Stead, L. F. (2004) Physician advice for smoking cessation. Cochrane Database of Systematic Reviews, issue 4, CD000165. Update Software.

Lancaster, T. \& Stead, L. F. (2005a) Individual behavioural counselling for smoking cessation. Cochrane Database of Systematic Reviews, issue 2, CD001292. Wiley InterScience.

Lancaster, T. \& Stead, L. F. (2005b) Self help interventions for smoking cessation. Cochrane Database of Systematic Reviews, issue 3, CD001118. Wiley InterScience.

Lancaster, T., Hajek, P., Stead, L. F., et al (2006) Prevention of relapse after quitting smoking: a systematic review of trials. Archives of Internal Medicine, 166, 828-835.

Lasser, K., Boyd, J. W., Woolhandler, S., et al (2000) Smoking and mental illness. A population-based prevalence study. JAMA, 284, 2606-2610.

Lawn, S. \& Pols, R. (2005) Smoking bans in psychiatric settings? A review of the research. Australian and New Zealand Journal of Psychiatry, 39, 866-855.

Martinez-Raga, J., Keaney, F., Sutherland, G., et al (2003) Treatment of nicotine dependence with bupropion SR: review of its efficacy, safety and pharmacological profile. Addiction Biology, 8, 13-21.

McNeill, A. (2004) Smoking and Patients with Mental Health Problems. Health Development Agency.

Medicines and Healthcare products Regulatory Agency \& Committee on Safety of Medicines (2005) Report of the Committee on Safety of Medicines Working Group on Nicotine Replacement Therapy. MHRA.

Raftery, J. (2001) NICE: faster access to modern treatments? Analysis of guidance on health technologies. BMJ, 323, 1300-1303.

Rice, V. H. \& Stead, L. F. (2008) Nursing interventions for smoking cessation. Cochrane Database of Systematic Reviews, issue 1, CD001188. Wiley InterScience. 
Richmond, R. \& Zwar, N. (2003) Review of bupropion for smoking cessation. Drug and Alcohol Review, 22, 203-220.

Schall, U. S., Pries, E., Katta, T., et al (1996) Pharmacokinetic and pharmacodynamic interactions in an outpatient maintenance therapy of intravenous heroin users with levomethadone. Addiction Biology, 1, 105-113.

Seppala, N. H., Leinonen, E. V., Lehtonen, M. L., et al (1999) Clozapine serum concentrations are lower in smoking than in non-smoking schizophrenic patients. Pharmacology and Toxicology, 85, 244-246.

Stead, L. \& Lancaster, T. (2005) Group behaviour therapy programmes for smoking cessation. Cochrane Database of Systematic Reviews, issue 2, CD001007. Wiley InterScience.

Stead, L. \& Lancaster, T. (2007) Interventions to reduce harm from continued tobacco use. Cochrane Database of Systematic Reviews, issue 3, CD005231. Wiley InterScience.

Stead, L., Perera, R. \& Lancaster, T. (2006) Telephone counselling for smoking cessation. Cochrane Database of Systematic Reviews, issue 2, CD001007. Wiley InterScience.

Stead, L., Perera, R. \& Lancaster, T. (2007) A systematic review of interventions for smokers who contact quitlines. Tobacco Control, 16, 3-8.

Stead, L., Perera, R., Bullen, C., et al (2008) Nicotine replacement therapy for smoking cessation. Cochrane Database of Systematic Reviews, issue 1, CD000146. Wiley InterScience.

Steinberg, M. L., Williams, J. M. \& Ziedonis, D. M. (2004) Financial implications of cigarette smoking among individuals with schizophrenia. Tobacco Control, 13, 206.

Strasser, A. A., Kaufmann, V., Jepson, C., et al (2005) Effects of different nicotine replacement therapies on postcessation psychological responses. Addictive Behaviour, 30, 9-17.

Taylor, A. H., Ussher, M. H. \& Faulkner, G. (2007) The acute effects of exercise on cigarette cravings, withdrawal symptoms, affect and smoking behaviour: a systematic review. Addiction, 102, 534-543.

Taylor, D., Paton, C. \& Kerwin, R. (2007) Maudsley Prescribing Guidelines (9th edn). Informa Healthcare.

Wang, D., Connock, M., Barton, P., et al (2008) 'Cut down to quit' with nicotine replacement therapies in smoking cessation: a systematic review of effectiveness and economic analysis. Health Technology Assessment, 12(2), 1-156.

West, R. \& Shiffman, S. (2001) Effect of oral nicotine dosing forms on cigarette withdrawal symptoms and craving: a systematic review. Psychopharmacology, 155, 115-122.

West, R., McNeill, A. \& Raw, M. (2004) Smoking Cessation Guidelines for Scotland: 2004 Update. NHS Health Scotland \& ASH Scotland.

White, A. R., Rampes, H. \& Campbell, J. L. (2006) Acupuncture and related interventions for smoking cessation. Cochrane Database of Systematic Reviews, issue 1, CD000009. Wiley InterScience.

Wilhelm, K., Arnold, K., Niven, H., et al (2004) Grey lungs and blue moods: smoking cessation in the context of lifetime depression history. Australian and New Zealand Journal of Psychiatry, 38, 896-905.

Wilhelm, K., Wedgwood, L., Niven, H., et al (2006) Smoking cessation and depression: current knowledge and future directions. Drug and Alcohol Review, 25, 97-107.

Williams, J. M. \& Foulds, J. (2007) Successful tobacco dependence treatment in schizophrenia. American Journal of Psychiatry, 164, 222-227.

Williams, J. M. \& Hughes, J. R. (2003) Addressing tobacco use in mental health and addiction settings. Psychiatric Annals, 33, 457-466.

Woolacott, N. F., Jones, L., Forbes, C. A., et al (2002) The clinical effectiveness and cost-effectiveness of bupropion and nicotine replacement therapy for smoking cessation: a systematic review and economic evaluation. Health Technology Assessment, 6(4), 1-183.

Zullino, D. F., Delssert, D., Eap, C. B., et al (2002) Tobacco and cannabis cessation can lead to intoxication with clozapine or olanzapine. International Clinical Psychopharmacology, 17, 141-143.

Zwartz, L. H., Noell, J. W., Schroeder, S. W., et al (2006) A randomised control study of a fully automated internet based smoking cessation programme. Tobacco Control, 15, 7-12.

\section{MCQs}

1 Evidence does not exist for the following smokingcessation interventions:

a simple advice by a physician

b smoking cessation advice and/or counselling given by nurses

c acupuncture

d group therapy

e telephone support.

2 Which of the following is false?

a half of smokers with mental illness have expressed a desire to stop smoking

b smoking increases the risk of developing future mental illness

c increased smoking in those with mental illness is responsible for a large proportion of this group's excess mortality

d smoking cessation treatments are ineffective for those hospitalised with mental illness

e those who recover from mental illness are not at increased risk of subsequent smoking.

3 The following drugs are not affected by smokingrelated liver enzyme induction:

a olanzapine

b risperidone

c mirtazapine

d clozapine

e diazepam.

4 The following interventions are not helpful in smoking cessation:

a NRT

b nortriptyline

c fluoxetine

d bupropion

e CBT.

5 The following interventions are not helpful for assisting those with schizophrenia to stop smoking:

a NRT

b bupropion

c combination NRT and bupropion

d harm reduction with NRT

e SSRIs.

\begin{tabular}{|c|c|c|c|c|}
\hline \multicolumn{5}{|c|}{ MCQ answers } \\
\hline 1 & 2 & 3 & 4 & 5 \\
\hline a $F$ & a $F$ & a $F$ & a $F$ & a $F$ \\
\hline b F & b F & $\mathrm{b} \mathrm{T}$ & b F & $b \mathrm{~F}$ \\
\hline c $\mathrm{T}$ & c F & C F & c $\mathrm{T}$ & c $\mathrm{F}$ \\
\hline d F & d $\mathrm{T}$ & d F & d F & d F \\
\hline e $F$ & e F & e F & e F & e $\mathrm{T}$ \\
\hline
\end{tabular}

